\title{
CIDADANIA AMBIENTAL E ATIVISMO JUVENIL
}

\author{
ENVIRONMENTAL CITIZENSHIP AND YOUTH ACTIVISM
}

Pedro Reis ${ }^{1}$

Recebido: fevereiro/2021 Aprovado: abril/2021

Resumo: A capacidade de um cidadão agir na sociedade como agente de mudança constitui um elemento importante da cidadania ambiental. Este artigo discute o conceito de ativismo e a importância das iniciativas de ativismo no desenvolvimento da disposição e das competências dos cidadãos para um envolvimento crítico, ativo e democrático na prevenção e resolução de problemas ambientais. São apresentados exemplos de iniciativas de ativismo ambiental juvenil. Também se discute a combinação possível e desejável de ativismo juvenil e ciência cidadã, como um catalisador do empoderamento dos cidadãos para a participação no esforço global do desenvolvimento sustentável e a assunção da responsabilidade pelas gerações futuras. $O$ ativismo juvenil representa um elemento-chave na Educação para a Cidadania Ambiental, permitindo que os alunos exerçam os seus direitos e deveres ambientais e desenvolvam conhecimentos, capacidades, valores e atitudes que os capacitem como solucionadores de problemas capazes de enfrentarem os problemas ambientais contemporâneos. Logo, não se trata de entender a participação dos jovens apenas em termos do direito individual de expressarem a sua voz em processos decisórios públicos - orientados pelos adultos e baseados em instituições - mas, também, de participarem como cidadãos ativos no seu quotidiano, assumindo-se como membros das suas comunidades e partilhando papéis e responsabilidades.

Palavras-chave: Cidadania ambiental; Ativismo juvenil; Ação sociopolítica; Problemas ambientais; Ciência cidadã.

Abstract: The citizen's capacity to act in society as an agent of change constitutes an important element of environmental citizenship. This article discusses the concept of activism and the importance of activism initiatives in developing citizens' willingness and skills for critical, active and democratic involvement in preventing and solving environmental problems. Examples of youth environmental activism initiatives are presented. The possible and desirable combination of youth activism and citizen science as a catalyst for citizens' empowerment to participate in the global effort of sustainable development and the assumption of responsibility for future generations is also discussed. Youth activism represents a key element in Environmental Citizenship Education, enabling students to exercise their environmental rights and duties and to develop knowledge, skills, values and attitudes that empower them as problem solvers capable of addressing contemporary environmental problems. Therefore, it is not only a matter of understanding young people's participation in terms of their individual right to express their voice in public decisionmaking processes - adult-driven and institution-based - but also of participating as active citizens in their daily lives, assuming themselves as members of their communities and sharing roles and responsibilities.

Keywords: Environmental citizenship; Youth activism; Sociopolitical action; Environmental problems; Citizen science.

\section{Prefácio}

Este artigo apresenta uma mensagem de esperança em melhores dias. Constitui uma reflexão sobre o poder da educação e dos cidadãos na luta contra ideologias autoritárias e

1 (iD https://orcid.org/0000-0002-9549-2516 - Doutor em Educação - Didática das Ciências (FCUL). Professor Associado com Agregação, Instituto de Educação da Universidade de Lisboa (IE-ULisboa), Lisboa, Portugal. Alameda da Universidade, 1649-013 Lisboa, Portugal. E-mail: preis@ie.ulisboa.pt 
estruturas que restringem os direitos e o acesso daqueles que afirmam servir. Constitui um manifesto contra o fatalismo, o pessimismo, a apatia ou a complacência perante a degradação ambiental e a injustiça social, através da apresentação de uma abordagem educativa promotora de questionamento sobre os problemas ambientais da sociedade atual e do empoderamento dos jovens/cidadãos para a transformação social no sentido da construção de um mundo mais justo e sustentável. Trata-se de uma abordagem educativa que nos interpela como cidadãos, permitindo aos alunos e aos seus professores assumirem um papel de cidadãos críticos, mobilizados contra os problemas ambientais e implicados ativamente na melhoria da sociedade.

Este artigo apresenta uma perspetiva humanista da educação em ciências que combina a abordagem de conteúdos científicos com a educação para a cidadania ambiental e o desenvolvimento holístico dos jovens/cidadãos. Desta forma, a educação em ciências é assumida como um pretexto e um contexto para o desenvolvimento de conhecimentos, capacidades, valores e atitudes que capacitem os jovens/cidadãos para enfrentarem os problemas, os desafios e as injustiças do seu quotidiano. Nesta abordagem educativa, as ciências são apresentadas de uma forma socialmente contextualizada que reforça a perceção dos alunos acerca da importância e da relevância da educação em ciências para a resolução dos problemas que afetam as suas/nossas comunidades. Segundo esta abordagem, o sucesso dos alunos na escola e na vida não depende apenas do sucesso académico, mas, fundamentalmente, da vivência de oportunidades de desenvolvimento intra e interpessoal e de exercício de cidadania em situações que consideram socialmente relevantes. Os alunos necessitam que os incentivem a assumir a responsabilidade pela promoção do bem-estar nas comunidades e nos ecossistemas em que vivem.

\section{Introdução}

O exercício da Cidadania Ambiental está fortemente associado à capacidade do cidadão agir na sociedade como agente de mudança (HADJICHAMBIS; REIS, 2020; HADJICHAMBIS ET AL., 2020; REIS, 2020), o que depende do desenvolvimento da disposição e da competência do indivíduo para um envolvimento crítico, ativo e democrático na prevenção e na resolução de problemas ambientais. Existe um apelo a uma cidadania bem informada e empoderada para tomar as ações apropriadas à gravidade dos problemas ambientais que afetam o nosso mundo (GRAY ET AL., 2009; HODSON, 2003). No entanto, muitos cidadãos não se sentem suficientemente empoderados para participar em processos de tomada de decisão sobre controvérsias socioambientais e, ao mesmo tempo, a confiança nos políticos tem diminuído e a apatia política tem ganho terreno (HODSON, 2014). Ao longo da última década, o surgimento de práticas governamentais autoritárias, o fracasso dos movimentos populares em substituir regimes não democráticos e o aumento dos movimentos populistas em todo o mundo têm alimentando preocupações sobre uma possível 'recessão democrática' (DIAMOND, 2015). Parte do sucesso destes movimentos tem sido atribuído a falhas na mobilização da participação política dos jovens (SCHULZ ET AL., 2018; JACKSON ET AL., 2016).

O conceito de empoderamento aparece frequentemente associado à capacitação dos cidadãos para a participação e a ação sociopolítica no sentido da mudança social (SCHUTZ, 
2019). No sentido mais simples e geral, significa capacitar um indivíduo ou um grupo a fazer alguma coisa. Este conceito surge a propósito dos movimentos sociais da década de $1960 \mathrm{e}$ aparece no contexto de movimentos de protesto social, ancorado numa filosofia que priorizava os pontos de vista dos povos oprimidos, permitindo-lhes não apenas expressarem-se, mas também ganhar poder e superar a dominação (SCHUTZ, 2019).

O envolvimento cívico depende dos jovens e da sua "motivação para participarem em atividades cívicas, da sua confiança na eficácia da sua participação, e das suas crenças sobre a sua própria capacidade de se envolverem ativamente" (SCHULZ ET AL., 2018, p. 72). A investigação mostra que o envolvimento cívico de um aluno pode ser apoiado e incentivado pela escola, com a ajuda de: (1) climas abertos da escola, (2) estruturas democráticas nas escolas, e (3) oportunidades precoces de participação ativa, da promoção do conhecimento cívico dos alunos e da predisposição em envolverem-se em atividades cívicas no futuro (SCHULZ ET AL., 2018; PANCER, 2015; ROTH; CALABRESE-BARTON, 2004). Portanto, a educação constitui um elemento-chave para contrariar os baixos níveis de envolvimento cívico dos jovens, nomeadamente através da promoção do ativismo democrático (HODSON, 2014).

A participação das crianças e dos jovens também não pode ser entendida isoladamente dos contextos sociais, culturais e políticos em que ocorre. As crianças e os jovens são segregados do mundo adulto, experimentando relações desiguais de poder com os adultos e sendo integrados num sistema educativo em que não têm poder e onde a sua agência não é habilitada (PERCY-SMITH; THOMAS, 2010). Grande parte das suas vidas é controlada e limitada por adultos. E esta situaação não resulta da falta de capacidades ou de perceções erróneas das crianças, mas das posições sociais que lhes são atribuídas (ALDERSON; GOODEY, 1996).

Enquanto nos países ocidentais (mundo minoritário) a participação dos jovens é frequentemente entendida como o direito à expressão de pontos de vista (consulta) em processos públicos de tomada de decisão, nos países em desenvolvimento (mundo maioritário) a participação costuma ter um significado mais amplo de contribuição ativa para a família e para a comunidade (PERCY-SMITH; THOMAS, 2010). Historicamente, os adultos dos países ocidentais veem na criança falta de agência e necessidade de proteção. Nestes países, as crianças costumam ser limitadas pelos adultos na sua capacidade de moldar as suas vidas e as suas comunidades, cabendo aos adultos agir no que consideram ser o melhor interesse das crianças. Pelo contrário, as crianças do mundo maioritário revelam capacidades significativas como cidadãos, sendo capazes de assumir responsabilidades e papéis ativos nas suas comunidades (MCDONNELL, 2005). No mundo maioritário, apesar das crianças trabalhadoras serem frequentemente vistas como negligenciadas ou vulneráveis, vários exemplos mostram como essas crianças podem ser extremamente ativas, competentes e participativas (PERCY-SMITH; THOMAS, 2010; WHITE; CHOUDHURY, 2010). Assim, enquanto que nos países ocidentais, as crianças com menos de 10 anos são frequentemente excluídas das situações de tomada de decisão (KIRBY; LAWS, 2010), noutras partes do mundo as crianças dessa idade podem ser chefes de família (PELLS, 2010). Enquanto para algumas crianças e jovens a participação pode abrir novas oportunidades e escolhas, para outros, vivendo em circunstâncias de conflito ou pobreza, pode constituir uma questão de sobrevivência, permitindo-lhes aceder a outros direitos na luta diária pela sobrevivência (PERCY-SMITH; THOMAS, 2010). 
As expectativas negativas da sociedade (nomeadamente, dos adultos) relativamente às capacidades de crianças e jovens constituem um obstáculo significativo à sua participação, tornando-os passivos por causa da expectativa de que devam relegar nos seus pais a defesa dos seus interesses (TWUM-DANSO, 2010). O reconhecimento da capacidade de crianças e jovens e do seu potencial para a mudança social é essencial para neutralizar sua invisibilidade e impotência (MENEZES ET AL., 2012; YAMASHITA; DAVIES, 2010).

O contexto social em que as crianças e os jovens vivem é decisivo para o seu desenvolvimento, aprendendo através da interação com membros mais experientes das suas comunidades, incluindo outras crianças (ROGOFF, 1990; VALSINER, 2000; VYGOTSKY, 1978). Muitas das decisões marcantes para a vida dos indivíduos e das suas comunidades são tomadas durante o quotidiano, e não através da participação em estruturas políticas de governo. Logo, a participação social em contextos cotidianos pode ser mais empoderadora do que a participação em contextos públicos de tomada de decisão (HART, 1992; WHITE; CHOUDHURY, 2010).

Segundo Stevenson (2016) e Peterson (2018), a construção de comunidades de jovens fortemente implicadas na promoção do bem-estar individual e coletivo e na eliminação de injustiças sociais poderá ser alcançada através de uma abordagem faseada que implica:

1. Aproximar - Apenas através da aproximação aos problemas sociais e ambientais complexos que afetam as comunidades e a sociedade se consegue compreendê-los e elevar o grau de preocupação dos cidadãos. A proximidade relativamente aos problemas e às experiências de quem os vive permite compreender a sua urgência e complexidade, bem como a rede intrincada de fatores que influenciam essas realidades.

2. Mudar a narrativa - A compreensão de um problema complexo e a identificação com as comunidades por ele afetadas, aumenta o grau de preocupação dos jovens relativamente a essa questão e conduz a uma mudança da narrativa que mantêm sobre essa problemática. Através desta nova narrativa consegue-se contribuir para a mudança/transformação ativa da narrativa dominante que sustenta o status quo e a interrupção de sistemas amplos de injustiça.

3. Ficar desconfortável - A mudança da narrativa sobre um problema, com a consequente tomada de consciência crítica, desencadeia uma dissonância cognitiva e emocional (FESTINGER, 1957; HARMON-JONES; HARMON-JONES, 2007), que resulta num estado de desconforto, raiva, medo, angústia e/ou ansiedade cuja intensidade dependerá da importância e da discrepância entre as cognições. Uma vez disparada a dissonância, os jovens (e quaisquer outros cidadãos) acionam mecanismos psicológicos diversos para reduzir ou eliminar a dissonância. Estes mecanismos podem passar, por exemplo, pela apatia ou pela ignorância consciente (quando se opta por nem se querer saber perante sentimentos de impotência) ou pela vontade de contribuir ativamente para a resolução do problema (quando os jovens se sentem motivados, capacitados e empoderados para tal) (BERILA, 2016).

4. Cultivar a esperança - A mudança social não depende apenas da proximidade e do aprofundamento da consciência crítica, passando também pelo impulso 
proporcionado por um forte propósito e pela esperança que motivam a associação com outros jovens/cidadãos que partilham a mesma narrativa, a mesma visão do mundo e as mesmas estratégias de ação para alcançar essa visão comum. Esta etapa envolve o reconhecimento dos pontos fortes de cada indivíduo e a sua conjunção no apoio à ação coletiva.

A capacitação das crianças e dos jovens para a participação passa também pela experiência/contacto com diferentes modelos de participação e pelo consequente desenvolvimento de competências. Contudo, este contacto apenas é possível em comunidades em que os adultos: a) não trabalham ativamente contra a participação das crianças e dos jovens, por sentirem que estes não devem ser sobrecarregados ou que carecem de capacidade para tal, podendo incorrer em manipulações por terceiros; e b) não bloqueiam as oportunidades nem os desencorajam de participar, minando intencional ou involuntariamente as suas capacidades e fazendo com que se sintam incapazes de participar.

Hart $(1992,2008)$ propõe vários modelos de participação de crianças e jovens:

5. Manipulação - Trata-se de uma situação em que as crianças e os jovens são induzidos a defender causas que não compreendem ou sobre as quais não estão devidamente informados. Também acontece quando são convidados a opinar sobre determinada proposta, mas sem serem envolvidos, posteriormente, no processo de tomada de decisão ou sem lhes ser dado qualquer feedback.

6. Decoração - Acontece quando, por exemplo, as crianças e os jovens são aliciados para participarem em festas ou outros eventos em que devem utilizar t-shirts com determinada mensagem que não compreendem. Neste caso, são aliciados pelas bebidas ou qualquer aspeto interessante, e não pela causa.

7. Tokenismo - Situação em que aparentemente as crianças ou os jovens recebem voz, mas, de fato, têm pouco ou nenhum poder de decisão sobre o assunto ou o estilo de comunicá-lo, e pouca ou nenhuma oportunidade para formular as suas próprias opiniões. Trata-se de fazer apenas um esforço superficial ou simbólico para ser inclusivo para membros de minorias. Acontece, por exemplo, quando são convidados a participarem num painel de uma conferência sem que estejam preparados para tal, se conheçam os critérios utilizados para a sua seleção e sem que tenham sido mandatados pelos colegas que se pretende representarem. Neste caso, o evento não é organizado de forma participativa: as crianças e os jovens não se envolvem genuína e eficazmente no painel. Frequentemente, estas experiências são desagradáveis e estimulam a ideia de que a participação pode ser uma farsa.

8. Atribuídos, mas informados - Situações em que os adultos planeiam determinado evento e atribuem papéis às crianças ou aos jovens, mas em que estes estão informados, concordam e se sentem identificados com esses papéis.

9. Consultados e informados - Quando as crianças ou os jovens são consultados por adultos, mas de uma forma íntegra. O projeto é elaborado e executado por adultos, mas as crianças ou os jovens entendem o processo e as suas opiniões são tratadas 
com seriedade.

10. Processos iniciados por adultos, mas com decisões partilhadas com crianças ou jovens - Trata-se de uma situação de verdadeira participação em que, embora o projeto seja iniciado por adultos, a tomada de decisões é partilhada com as crianças ou os jovens.

11. Projetos iniciados e dirigidos por crianças ou jovens - Quando as crianças ou os jovens concebem e implementam planos/projetos complexos.

12. Projetos iniciados por crianças ou jovens em que as decisões são partilhadas com adultos - Trata-se de situações em que os adultos são convidados por grupos de jovens para ajudarem a concretizar determinados projetos que consideram socialmente relevantes. Neste caso, os jovens constituem-se como cidadãos, membros de uma comunidade que inclui adultos e outros jovens com os quais se podem associar para lutarem por determinados objetivos.

Outro conceito-chave na capacitação de crianças e jovens para a ação é o de agência, ou seja, a capacidade individual e coletiva para se agir de forma a obterem-se determinados resultados desejados e a transformarem-se as condições externas que os condicionam (GINWRIGHT, 2015). Contudo, o conceito de agência não é consensual entre os especialistas. Nesta lição utiliza-se a definição proposta por Greene e Nixon (2020). Segundo estes autores, a capacidade das crianças ou dos jovens atuarem como agentes muda ao longo do tempo, mas esta mudança não está vinculada a nenhuma idade ou estágio. A agência humana implica a capacidade de refletir e tomar decisões: está associada a autodeterminação, não sendo simplesmente desencadeada por gatilhos ou recursos externos. A agência é sempre dependente do contexto, emergindo do desenvolvimento das transações com o ambiente social e material e sendo moldada tanto pela atividade no mundo quanto pelo uso da linguagem. Inevitavelmente, é limitado pelas realidades biológicas, ambientais e temporais. Crenças e intenções são reais, não ilusórias e podem ter um impacto direto no que o indivíduo faz.

Assim, pode-se contribuir para o desenvolvimento da agência nos jovens através da criação de espaços para a expressão da sua voz e da identificação de formas dos jovens poderem envolver-se nas problemáticas das suas comunidades (HART, 2008). A disponibilização de projetos tangíveis para a mudança local que sejam simultaneamente exequíveis e empoderadores facilitam o desenvolvimento da convicção de que a mudança é possível.

Segundo alguns autores (FREIRE, 1970), as populações oprimidas não possuem a agência ou a capacidade política para se libertarem das narrativas dominantes (para se emanciparem), necessitando da interação com outros membros da comunidade que possuam essa capacidade. Contudo, outros autores, acreditam que qualquer cidadão tem a capacidade de contribuir para a mudança social, enfrentando a sua própria dor e recusando-se a permanecer complacente com a narrativa dominante (GRAMSCI, 1971).

\subsection{Conceito de Ativismo}

O ativismo é um conceito problemático, frequentemente associado a imaginários sociais 
de: a) ações radicais e por vezes violentas de grupos fanáticos (DAVIES ET AL., 2019); b) práticas de doutrinação que não respeitam pontos de vista diferentes (ALSOP; BENCZE, 2009); e c) ao espetáculo do confronto de polícias e manifestantes em espaços públicos (CALABRESE ET AL., 2010). Em alguns contextos académicos (sob a influência de Paulo Freire), o termo 'ativismo' está associado à prática desprovida de teoria - ou a ação sem reflexão (FREIRE, 1970). Na opinião de Freire, a transformação do mundo requer um processo dialético entre prática e teoria (entre ação e reflexão): teoria desprovida de prática consiste em verbalismo simples; e a prática desprovida de teoria resulta em ativismo cego. No entanto, nesta lição, o 'ativismo' refere-se a um processo de resolução coletiva, democrática, fundamentada em investigação e negociada de problemas socioambientais.

A ação comunitária informada (fundamentada em investigação) é frequentemente considerada um aspeto importante da literacia científica (HODSON, 1998), capacitando os alunos como críticos e produtores de conhecimento, em vez de colocá-los no papel de consumidores de conhecimento, como as práticas de ciência escolar parecem frequentemente encorajar (COLUCCI-GRAY; CAMINO, 2014; REIS, 2014; BENCZE; SPERLING, 2012). Este conceito mais amplo de literacia científica inclui o desenvolvimento nos alunos da "capacidade e do compromisso de tomarem ações apropriadas, responsáveis e efetivas sobre questões de interesse social, económico, ambiental e moral-ético" (HODSON 2003, p. 658). Envolve o exercício dos direitos e deveres ambientais dos alunos, bem como a identificação das causas estruturais subjacentes à degradação ambiental e aos problemas ambientais, desenvolvendo a disposição e as competências para o envolvimento crítico e ativo e a participação cívica para lidar com essas causas estruturais, agindo individual e coletivamente de forma democrática e tendo em conta a justiça inter e intra geracional (HADJICHAMBIS; REIS, 2020). Os problemas sociais e ambientais atuais só podem ser resolvidos através de currículos de ciências orientados para a ação sociopolítica, a fim de "produzir ativistas: pessoas que lutarão pelo que é certo, bom e justo; pessoas que trabalharão para reformular a sociedade segundo pautas mais justas socialmente; pessoas que trabalharão vigorosamente no melhor interesse da biosfera" (HODSON, 2003, p. 645). Nos últimos 15 anos, vários autores têm contribuído para o desenvolvimento desse objetivo, incluindo: Deborah Tippins, Michael Mueller, Michiel van Eijck e Jennifer Adams (2010), Jean e Laurence Simonneaux (2012), Larry Bencze (2008), Reis (2013), Steve Alsop e Larry Bencze (2014) e Wolff-Michael Roth e Angela Calabrese-Barton (2004).

O ativismo é frequentemente associado a um tipo específico de iniciativas de ciência cidadã. O termo ciência cidadã tem sido usado há décadas para descrever a participação do público em estudos científicos autênticos (MUELLER; TIPPINS, 2015), com o objetivo amplo de promover a literacia científica e ecológica dos alunos em ambientes escolares formais mais amplos (FAZIO; KARROW, 2015). Tradicionalmente, a ciência cidadã tem sido caracterizada como uma abordagem de cima para baixo, envolvendo projetos propostos e iniciados por cientistas e agências governamentais que recrutam membros da comunidade para recolherem dados sobre questões pouco relevantes para a vida dos cidadãos. No entanto, durante os últimos anos e sob a influência da educação científica crítica, a ciência cidadã - combinada com o ativismo - foi reformulada como uma abordagem pedagógica de baixo para cima, destinada a promover o interesse dos alunos pela comunidade, pelo ambiente, pela aprendizagem ao longo 
da vida, pela democracia e pela justiça social (BRITTON; TIPPINS, 2015; REIS, 2020; ROTH; LEE, 2002). Esta abordagem recorre à educação como um contexto para o desenvolvimento das competências e do envolvimento comunitário dos alunos, incentivando-os a serem cientistas cidadãos ativos que contribuem para o bem-estar das suas comunidades (BRITTON; TIPPINS, 2015). A ideologia por trás desta combinação de ciência cidadã e ativismo coloca ênfase na aprendizagem acerca da saúde da comunidade local, desenvolvendo currículos socialmente responsáveis, atenuando as fronteiras entre as disciplinas escolares e derrubando os muros da escola - facilitando a ligação entre a aprendizagem escolar e o espaço fora da escola onde os alunos e suas famílias vivem (BRITTON; TIPPINS, 2015; REIS, 2020; RODRÍGUEZ, 2015; MARTINEZ; ALSOP, 2014). Desta forma, a ciência cidadã não se limita apenas à recolha e análise de dados brutos sobre fenómenos naturais. De acordo com esta perspetiva, os alunos podem ser cidadãos ativos, implicados criticamente na aprendizagem acerca de questões eco-sociocientíficas e comprometidos com a disseminação e a denúncia da base não científica do preconceito e da discriminação (REIS ET AL., 2015; MUELLER; TIPPINS, 2012). Os alunos passam de uma posição de aprendizagem para o envolvimento em ações de cidadania e práticas de ciência através de ativismo (HAVERKOS, 2015).

A ciência cidadã combinada com o ativismo juvenil promove uma compreensão mais profunda de como a ciência funciona e constitui um poderoso catalisador para a capacitação e o empoderamento dos futuros cidadãos com a disposição e as capacidades de nível superior para a participação no esforço global da sustentabilidade e a assunção da responsabilidade pelas gerações futuras. $O$ ativismo democrático juvenil desenvolve a literacia científica crítica dos jovens, permitindo que as pessoas "pensem por si mesmas e cheguem às suas próprias conclusões sobre uma série de questões que têm uma dimensão científica, tecnológica e/ou ambiental" (HODSON, 2011, p. 28). A literacia científica crítica permite que os alunos "tomem ações apropriadas, responsáveis e eficazes em questões de interesse social, económico, ambiental e moral-ético" (HODSON 2011, P. 28), aumentando a sua capacidade de fazer escolhas em vez de aceitar as prescrições de outros.

\subsection{Apoio ao Ativismo Juvenil}

Segundo Sleeter e Cornbleth (2011), o envolvimento dos jovens em ativismo democrático requer que os alunos se sintam como tendo os direitos, as responsabilidades e as competências para participarem em processos complexos de pensamento, tomada de decisão e resolução de problemas. Estas competências e disposições para o ativismo democrático não são promovidas através de contribuições particulares de unidades curriculares ou atividades de sala de aula. Elas são desenvolvidas ao longo do tempo, através de experiências repetidas de aprendizagem ativa em contextos formais e informais; experiências que vão além da 'aplicação de conhecimento' aos contextos quotidianos - como muitos documentos do currículo escolar propõem - e que apoiam a aprendizagem através da ação sociopolítica (ALSOP; BENCZE, 2014). 0 ativismo requer o desenvolvimento de uma atmosfera de responsabilidade e compromisso compartilhados e uma relação colaborativa entre as escolas e as comunidades na tentativa de encontrar soluções apropriadas para os problemas que consideram importantes e socialmente relevantes (HODSON, 2014). 
O programa STEPWISE ("Science and Technology Education Promoting Well-being for Individuals, Societies and Environments") desenvolvido por Larry Bencze, oferece um enquadramento para o currículo e o ensino centrado no envolvimento dos alunos em investigações autodirigidas e de fim-aberto, baseadas na sua própria investigação primária (estudos experimentais e correlacionais) e secundária (usando dados recolhidos por outras pessoas e disponibilizados na Internet) para desenvolver planos de ação centrados em questões sociocientíficas ou socioambientais (BENCZE, 2017). A ideia principal do STEPWISE é incentivar e empoderar os alunos para utilizarem a ciência e a tecnologia em ações para ajudar os outros e o planeta. Com o enquadramento STEPWISE, foram desenvolvidas muitas iniciativas ativistas em vários países e contextos educacionais com um impacto considerável nas competências de cidadania ativa dos alunos (ALSOP; BENCZE, 2014; BENCZE, 2017).

O projeto "WE ACT - Promoting Collective Activism on Socio-Scientific and SocioEnvironmental Issues" tem apoiado professores e alunos de vários países e níveis escolares na implementação de ações informadas e negociadas sobre problemas sociais e ambientais (CONCEIÇÃO ET AL., 2019; ESPAÑA-RAMOS; REIS, 2017; GARCÍA-BERMÚDEZ ET AL., 2014, 2017; REIS, 2014; REIS; TINOCA, 2018; SCHEID; REIS, 2016; WATANABE; REIS, 2019). Este projeto centra-se (1) na promoção de uma aprendizagem ativa baseada em investigação sobre problemas da vida real relacionados com ciência e tecnologia e (2) no estímulo da participação dos alunos em ações coletivas de resolução democrática de problemas (por exemplo, através de iniciativas baseadas em arte e na utilização de ferramentas da Web 2.0). Baptista, Reis e Andrade (2018) apresentam e discutem um exemplo de ativismo juvenil - desenvolvido no âmbito do WE ACT - centrado num problema ambiental específico identificado por crianças: o colapso das colónias de abelhas numa área rural de Portugal. Os ativistas eram 26 alunos de uma escola primária com idades entre 8 e 10 anos. Durante um período de dois meses, os alunos envolveram-se na identificação de possíveis causas e soluções para o problema selecionado. As pesquisas realizadas pelos alunos, combinadas com o seu conhecimento das práticas agrícolas utilizadas pelas suas famílias, permitiram reconhecer a inadequação dessas práticas e aprender sobre práticas alternativas ambientalmente sustentáveis. Como forma de desenvolver uma ação coletiva na sua comunidade local, os alunos escreveram um manifesto - usando argumentos focados no uso de pesticidas e expondo algumas práticas agrícolas locais como uma possível causa do desaparecimento das abelhas - e convidaram a população local a assiná-lo. Este manifesto foi proposto pelos alunos e assinado pela população durante uma sessão pública na escola. Funcionou como um compromisso de mudança das práticas agrícolas prejudiciais ao ecossistema e de adoção de metodologias mais sustentáveis para o ambiente. Esta iniciativa ativista facilitou o desenvolvimento de conhecimentos científicos e de capacidades para a ação, evidenciando a possibilidade de se promover o envolvimento de jovens alunos em ações coletivas de resolução de problemas sobre problemas ambientais.

Tanto em contextos formais como não formais, existem várias maneiras possíveis de os jovens se envolverem em ativismo na esfera privada e pública, nomeadamente: (1) iniciativas educativas destinadas a mudar o comportamento de outros cidadãos; (2) a organização de grupos de pressão responsáveis por escreverem e distribuírem manifestos/petições e boicotarem determinados produtos desenvolvidos por meio de práticas controversas; (3) 
iniciativas de voluntários destinadas à promoção de um mundo mais justo, ético e sustentável; (4) a proposta de soluções inovadoras para problemas locais, nacionais e/ou globais; e (5) a mudança dos seus próprios comportamentos (BAPTISTA ET AL., 2018; BENCZE, 2017; HODSON, 2014; REIS, 2013, 2020).

As abordagens baseadas na arte e as ferramentas da Web 2.0 podem ser bastante poderosas para a implementação de ativismo coletivo sobre controvérsias socioambientais (REIS, 2013). A pesquisa e a discussão inerentes ao desenvolvimento de exposições e representações dramáticas sobre questões socioambientais podem ser particularmente úteis, tanto em termos da aprendizagem dos conteúdos, dos processos e da natureza da ciência e da tecnologia, como do desenvolvimento cognitivo, social, político, moral e ético dos alunos (REIS; MARQUES, 2016; KOLST $\varnothing, 2001$ ). As exposições e as representações dramáticas sobre controvérsias socioambientais, como contexto dialógico, permitem levantar questões, suscitar reflexão pessoal e estimular discussões entre alunos e visitantes, transformando ambos em aprendizes e ativistas políticos (BRAUND; REISS, 2004; LEVINSON ET AL., 2008; LINHARES; REIS, 2017; REIS; MARQUES, 2016; REIS ET AL., 2020). O desenvolvimento das exposições cria uma oportunidade para os alunos participarem em ativismo sobre problemas ambientais específicos, incentivando os visitantes a agirem (REIS; MARQUES, 2016).

Durante as últimas duas décadas, em muitos países, movimentos sociais têm recorrido às ferramentas da Web 2.0 para romperem com a agenda mediática dominante, estabelecerem ligações entre ativistas e movimentos e criarem novas formas de organização e ação sociopolítica (CANDÓN-MENA; BENÍTEZ-EYZAGUIRRE, 2016). Plataformas e redes sociais como o Facebook, o Instagram, o Snapchat, o Twitter e o YouTube têm permitido abrir brechas nos monopólios mediáticos, controlados por estados ou grupos económicos, criando e facilitando o acesso a um ciberespaço mais democrático e participativo e, consequentemente, dando poder a muitas pessoas que não o conseguiriam ter antes da era digital. Estas ferramentas digitais permitem que muitos cidadãos permaneçam conectados, partilhem experiências e opiniões e consigam contactar com pessoas com quem, de outra forma, não conseguiriam interagir. Mas também apresentam desvantagens, permitindo distribuir propaganda a milhões de pessoas, distraindo-as de questões importantes, estimulando o ódio e o fanatismo, minando a confiança social, fomentando dúvidas sobre a ciência e controlando o comportamento e a vida dos cidadãos (ASHLEY, 2020; LANIER, 2018; VAIDHYANATHAN, 2018). Contudo, as tecnologias por si só não têm o poder de transformar a participação e o envolvimento dos cidadãos na sociedade. Tudo depende da forma como estas ferramentas são utilizadas pela sociedade. Logo, novas lutas sociais têm acontecido com o recurso à Internet e às TIC, fazendo da informação um instrumento de poder (KELLNER, 2006). A facilidade de acesso à Internet e de construção e divulgação de conteúdos através da Web 2.0 permitem tanto a democratização no acesso à informação como a manipulação da informação por grupos específicos com o objetivo de modularem discurso e a opinião pública, desencadeando um movimento designado como desordem da informação (WARDLE, 2019; WARDLE; DERAKHSHAN, 2017) que ganha particular relevância em comunidades com baixos níveis de literacia mediática (LOPES, 2019). Esta desordem de informação, resultante da difusão de grandes quantidades de conteúdos falsos ou incorretos, não é um fenómeno novo, mas assumiu novas proporções com o aparecimento das redes sociais 
numa sociedade em rede (IRETON; POSENTTI, 2018). A promoção da literacia mediática dos cidadãos, entendida como a capacidade de aceder, analisar, avaliar, criar e fazer uso ativo de todas as formas de comunicação (BULGER; DAVISON, 2018), constitui um meio de combater os problemas resultantes da desordem da informação (IRETON; POSENTTI, 2018; WARDLE, 2019).

As ferramentas da Web 2.0 podem ter um forte impacto no empoderamento cultural, social e político dos cidadãos (KELLNER; KIM, 2010; ZORAS; BENCZE, 2014). Segundo vários autores, os meios interativos de transmissão de informações sobre problemas sociais e políticos (por exemplo, as redes sociais) são mais eficazes na promoção da participação cívica do que os media tradicionais (BACHEN ET AL., 2008; KAHNE ET AL., 2013; SEGERBERG; BENNETT, 2011). As ferramentas da Web 2.0, especialmente aquelas que permitem a comunicação coletiva (nomeadamente através de redes sociais), podem ser muito úteis para iniciativas de ativismo (STEGMANN ET AL., 2007), proporcionando a todos os cidadãos meios poderosos para expressar as suas vozes e visões, promovendo formas independentes de comunicação/intervenção e um modelo participativo de democracia (GARCÍA-BERMÚDEZ ET AL., 2014, 2017; KRSTOVIC, 2014; MARQUES; REIS, 2017a,b; SCHEID; REIS, 2016; ZORAS; BENCZE, 2014). Por meio destas formas de ativismo, cada aluno pode assumir um papel ativo na resolução de problemas, e não apenas o de um espectador que depende de especialistas para lhe apontarem direções.

Um ótimo exemplo de ativismo juvenil disseminado pelas redes sociais foi desencadeado pela adolescente sueca Greta Thunberg. Em agosto de 2018 (aos 15 anos), ela planeou uma greve na escola e um protesto no exterior do parlamento sueco, instando os políticos a agir sobre o aquecimento global, de forma a evitar as suas consequências desastrosas relacionadas com o aumento do nível do mar, eventos climáticos extremos, extinção de espécies, diminuição do fornecimento de água, custos económicos e crises humanitárias. Os seus protestos chamaram a atenção de todo o mundo e inspiraram um movimento global que levou a greves em muitos países e aumentou a consciência das pessoas sobre as mudanças climáticas e a necessidade de ações urgentes sobre este problema. A sua mensagem, disseminada pelas redes sociais e apresentada em fóruns internacionais, mobilizou crianças, adolescentes e adultos em todo o mundo, ações climáticas imediatas de políticos e responsáveis empresariais. Vários ativistas climáticos adolescentes, como Greta Thunberg, têm exercido pressão através de iniciativas disseminadas e organizadas através das redes sociais. O papel das crianças e dos jovens como agentes sociais e cidadãos ativos tem sido, em parte, impulsionado pela tomada de consciência das crianças do mundo minoritário dos problemas mundiais e pela constatação de que eles, em comparação com a grande maioria dos seus congéneres nos países em desenvolvimento, vivem vidas de enorme privilégio (MCDONNELL, 2005). Essa tomada de consciência tem motivado muitos jovens a participarem em iniciativas de ativismo social sobre problemáticas como o racismo, a falta de respeito pelos direitos das crianças e a degradação ambiental. Vários fatores da via moderna - como a televisão, a Internet e mudanças na educação de crianças e jovens - tem abalado o que McDonnell (2005) designa como o muro de ignorância forçada que cercou a infância na sociedade ocidental durante os últimos cem anos.

A investigação tem revelado que o ativismo dos alunos sobre controvérsias sociocientíficas e socioambientais tem um impacto positivo: (a) no seu conhecimento acerca dessas questões; (b) nas suas concepções sobre a natureza da ciência; (c) nas suas competências 
de investigação e de cidadania; e, eventualmente, (d) no bem-estar de indivíduos, sociedades e ambientes (BADER; LABERGE, 2014; BENCZE, 2017; BENCZE; CARTER 2011; DAVIES ET AL., 2019; REIS; TINOCA, 2018; ROTH; DÉSAUTELS 2002; ROTH; LEE, 2002; ZORAS; BENCZE, 2014). O envolvimento dos alunos em iniciativas de ativismo promove: (a) capacidades de comunicação através da troca de argumentos para determinadas ações; (b) capacidades de investigação científica durante a identificação das possíveis causas e soluções para problemas; (c) capacidades de pensamento crítico, através da resolução de problemas complexos; (d) criatividade, durante o desenvolvimento de propostas inovadoras para contextos únicos; (d) perseverança, através da compreensão de que a mudança implica tempo, esforço e dedicação; e (e) empoderamento, quando os alunos percebem que as suas ações podem ter um impacto positivo na sociedade (BENCZE, 2017; CARTER ET AL., 2014; CONCEIÇÃO ET AL., 2019; DAVIES ET AL., 2019; KRSTOVIC, 2014; MARQUES; REIS, 2017a, b; SCHALK, 2008; SCHUSLER; KRASNY, 2015).

\section{Conclusão}

O ativismo constitui um aspeto importante da Cidadania Ambiental, permitindo que os cidadãos se envolvam ativamente na resolução de problemas em vez de se limitarem a simples espectadores dependentes da opinião de especialistas. Consequentemente, o envolvimento dos alunos em iniciativas de ativismo representa um elemento-chave na Educação para a Cidadania Ambiental, criando um excelente contexto para o desenvolvimento de conhecimentos, capacidades, valores e atitudes que capacitam os cidadãos como agentes de mudança, capazes de conceber e implementar ações individuais e coletivas destinadas a contribuir para a resolução dos problemas ambientais contemporâneos (HADJICHAMBIS; REIS, 2020; REIS, 2020). As iniciativas de ativismo juvenil permitem que os alunos exerçam os seus direitos e deveres ambientais, compreendam as causas estruturais dos problemas ambientais e desenvolvam as competências necessárias para lidar com essas causas. Através do ativismo, os estudantes passam de uma posição de aprendizagem para uma nova posição de envolvimento ativo em atos de cidadania e práticas de investigação científica. Os alunos são, portanto, empoderados como produtores de conhecimento contextualizado e socialmente relevante, em vez de serem simples consumidores de conhecimento. Desta forma, as crianças e os jovens são considerados como agentes de mudança e cidadãos ativos, capazes de, com os seus colegas e com os adultos, poderem imaginar e criar projetos em torno de suas vidas, em vez de se limitarem a seguir os projetos que os adultos imaginam e concebem para eles. A participação autêntica envolve inclusão - em que o sistema muda para acomodar a participação e os valores das crianças e jovens - em vez de integração - em que as crianças e os jovens participam de formas e em estruturas predefinidas.

As iniciativas de ativismo juvenil têm o potencial de reforçar os laços entre a escola e as comunidades onde os alunos e as suas famílias vivem. Através destas iniciativas, os alunos desenvolvem perceções positivas sobre a importância e a relevância social de uma educação científica com currículos socialmente responsáveis, fortemente comprometidos com a saúde das comunidades e do ambiente.

O estudo dos recentes movimentos ativistas jovens pode lançar alguma luz sobre os 
fatores importantes na mobilização dos jovens para a participação política e, consequentemente, sobre como as escolas podem combater os baixos níveis de envolvimento cívico entre os jovens, nomeadamente, através da promoção do ativismo democrático.

A abordagem do ativismo juvenil assume a educação como uma força democratizante e catalisadora do desenvolvimento individual e da transformação social (DEWEY, 1916; FREIRE, 1970). Com essa abordagem, a escola torna-se um fórum vivo para o diálogo libertador e um contexto real para o exercício da Cidadania Ambiental. Existe uma urgência global por abordagens pedagógicas que incluam o ativismo juvenil como um passo central e fundamental para a promoção da Cidadania (nomeadamente, da Cidadania Ambiental). Para tal, torna-se necessário: a) garantir que crianças e jovens tenham oportunidades de participar de maneira significativa na sua vida diária, através da disponibilização de espaços informais e formais (em diferentes níveis, nomeadamente, casa, escola, comunidade, organizações e associações) em que possam articular suas próprias expressões de cidadania ativa por meio de diferentes formas de participação; b) estimular as crianças e jovens a assumirem níveis elevados de responsabilidade e de ação (que não se restrinjam a simples consultas) no exercício da sua agência como cidadãos ativos; e c) incentivar os adultos a assumirem um papel de facilitadores e defensores - e não de controladores - na realização de iniciativas de ativismo (envolvendo crianças, jovens e adultos) centradas em preocupações comuns e que facilitem 0 desenvolvimento de uma cultura de respeito e de confiança mútua.

Mudança climática, destruição de habitats, exploração descontrolada de recursos, desigualdade de riqueza, violações dos direitos humanos, desordem da informação e autoritarismo crescente são apenas alguns dos inúmeros problemas que ameaçam a estabilidade social e ambiental. Apenas através de uma cidadania ativa bem informada e empoderada para a ação se conseguirá fazer face à gravidade desses problemas. Ninguém espera que a escola consiga gerar cidadãos com todos os conhecimentos e com todas as capacidades necessárias à tomada de decisões e à ação fundamentada sobre qualquer problema. O que se pretende alcançar talvez constitua uma utopia: uma sociedade democrática na qual os cidadãos (independentemente da sua idade) colaborem e coloquem as suas diferentes competências ao serviço do bem-estar dos indivíduos, das comunidades e do ambiente, através de ações coletivas fundamentadas e focadas numa sociedade melhor. Mas os seres humanos necessitam de utopias que os desafiem e mobilizem para a ação.

\section{Referências Bibliográficas}

ALDERSON, P.; GOODEY, C. Research with disabled children: How useful is child-centered ethics? Children \& Society, n. 10, p. 106-16, 1996.

ALSOP, S.; BENCZE, L. Activism! Toward a more radical science and technology education. In: BENCZE, L.; ALSOP, S. (ed.). Activist science and technology education. Dordrecht, The Netherlands: Springer, 2014, p. 1-19.

ASHLEY, S. News Literacy and Democracy. New York: Routledge, 2020.

BACHEN, C. et al. Civic Engagement, Pedagogy, and Information Technology on Web Sites for 
Youth. Political Communication, v. 25, n. 3, p. 290-310, 2008.

BADER, B.; LABERGE, Y. Activism in science and environmental education: Renewing conceptions about science among students when considering socioscientific issues. In: BENCZE, L.; ALSOP, S. (ed.). Activist science and technology education. Dordrecht, The Netherlands: Springer, 2014, p. 419-433.

BAPTISTA, M. et al. Let's save the bees! An environmental activism initiative in elementary school. Visions for Sustainability, n. 9, p. 41-48, 2018.

BENCZE, L. Private profit, science and science education: Critical problems and possibilities for action. Canadian Journal of Science, Mathematics \& Technology Education, v. 8, n. 4, p. 297-312, 2008.

BENCZE, L. (ed.) Science and Technology Education Promoting Wellbeing for Individuals, Societies and Environments. Dordrecht, The Netherlands: Springer, 2017.

BENCZE, L.; CARTER, L. Globalizing students acting for the common good. Journal of Research in Science Teaching, v. 48, n. 6, p. 648-669, 2011.

BENCZE, J. L.; SPERLING, E. R. Student-teachers as advocates for student-led research-informed socioscientific activism. Canadian Journal of Science, Mathematics \& Technology Education, v. 12, n. 1, p. 62-85, 2012.

BERILA, B. Integration Mindfulness into Anti-Oppression Pedagogy. New York, NY: Routledge, 2016.

BRAUND, M.; REISS, M. (ed.). Learning science outside the classroom. London: Routledge Falmer, 2004.

BRITTON, S. A.; TIPPINS, D. J. Living History: Challenging Citizen Science and Youth Activism Through Historical Re-enacting. In: MUELLER, M. P.; TIPPINS, D. J. (ed). EcoJustice, Citizen Science and Youth Activism. Situated Tensions for Science Education. New York: Springer, 2015, p. 207222.

BULGER, M.; DAVISON, P. The Promises, Challenges, and Futures of Media Literacy. Journal of Media Literacy Education, v. 10, n. 1, p. 1-21, 2018.

CALABRESE BARTON, A.; TAN, E. It Changed Our Lives: Activism, Science, and Greening the Community. Canadian Journal of Science, Mathematics and Technology Education, v. 10, n. 3, p. 207-222, 2010.

CANDÓN-MENA, J.; BENÍTEZ-EYZAGUIRRE, L. (ed.) Activismo digital y nuevos modos de ciudadanía: Una mirada global. InCom-UAB Publicacions. Bellaterra: Institut de la Comunicació, Universitat Autònoma de Barcelona, 2016.

CARTER, L. et al. Transformative learning in science education: Investigating pedagogy for action. In: BENCZE, L.; ALSOP, S. (ed.). Activist science and technology education. Dordrecht, The Netherlands: Springer, 2014, p. 531-545.

COLUCCI-GRAY, L.; CAMINO, E. From knowledge to action? Re-embedding science learning within the planet's web. In: BENCZE, L.; ALSOP, S. (ed.). Activist science and technology 
education. Dordrecht, The Netherlands: Springer, 2014, p. 149-164.

CONCEIÇÃO, T. et al. La contaminación de los recursos hídricos como punto de partida para el activismo socio-científico. Revista Eureka sobre Enseñanza y Divulgación de las Ciencias, v. 16, n. 1, p. 1502, 2019.

DAVIES, I. et al. (ed.). Taking action for change: Educating for youth civic engagement and activism. York: University of York, 2019.

DEWEY, J. Democracy and education: An introduction to the philosophy of education. New York: Free Press, 1916.

DIAMOND, L. Facing up to democratic recession. Journal of Democracy, v. 26, n. 1, p. 141-155, 2015.

ESPAÑA-RAMOS, E.; REIS, P. El proyecto We Act como marco para formar ciudadanos competentes a través del activismo colectivo basado en la investigación. Enseñanza de las Ciencias, no extraordinario, p. 657-661, 2017.

Fazio, X.; Karrow, D. D. The Commonplaces of Schooling and Citizen Science. In: MUELLER, M. P.; TIPPINS, D. J. (ed). EcoJustice, Citizen Science and Youth Activism. Situated Tensions for Science Education. New York: Springer, 2015, p. 179-182.

FESTINGER, L. A Theory of Cognitive Dissonance. Stanford: Stanford University Press, 1957.

FREIRE, P. Pedagogia do oprimido. 1.ed. Rio de Janeiro: Paz e Terra, 1974.

GARCÍA-BERMÚDEZ, S. et al. Potencialidades y limitaciones de los entornos virtuales colaborativos y las herramientas web 2.0 en la promoción del activismo sobre cuestiones ambientales en estudiantes de básica secundaria. Uni/Pluriversidad, v. 41/14, n. 2, p. 502-507, 2014.

GARCIA-BERMUDEZ, S., et al. Promoción del activismo sobre cuestiones ambientales en estudiantes de básica secundaria a través de las herramientas web 2.0. Da Investigação às Práticas, v. 7, n. 2, p. 34-53, 2017.

GINWRIGHT, S. Hope and healing in urban education: How urban activists and teachers are reclaiming matters of the heart. New York: Routledge, 2015.

GRAMSCI, A. Selections from the Prison Notebooks. New York: International Publishers, 1971.

GRAY, D. et al. (ed.). Science, society and sustainability: Education and empowerment for an uncertain world. London: Routledge Research, 2009.

GREENE, S.; NIXON, E. Children as Agents in Their Worlds: A Psychological-Relational Perspective. New York: Routledge, 2020.

HADJICHAMBIS, A. CH.; REIS, P. Introduction to the conceptualisation of Environmental Citizenship for twenty-first century education. In HADJICHAMBIS, A. $\mathrm{CH}$. et al. (ed.). Conceptualizing Environmental Citizenship for 21st Century Education. Series "Environmental discourses in Science Education". Cham: Springer, 2020, p. 1-14.

HADJICHAMBIS, A. CH. et al. (ed.) Conceptualizing Environmental Citizenship for 21st Century 
Education. Series "Environmental discourses in Science Education". Cham: Springer, 2020.

HARMON-JONES, E.; HARMON-JONES, C. Cognitive Dissonance Theory after 50 years of development. Zeitschrift für Sozialpsychologie, v. 38, n. 1, p. 7-16, 2007.

HART, R. Children's Participation: From Tokenism to Citizenship. Florence, Italy: International Child Development Centre of UNICEF, 1992.

HART, R. Stepping back from 'the ladder': reflections on a model of participatory work with children. In: Reid, A. B. (ed.), Participation and Learning: Perspectives on Education and the Environment, Health and Sustainability. Dordrecht, The Netherlands: Springer, 2008, p. 19-31.

HAVERKOS, K. Living History-Challenging Citizen Science and Youth Activism Through Historical Re-enacting. In: MUELLER, M. P.; TIPPINS, D. J. (ed). EcoJustice, Citizen Science and Youth Activism. Situated Tensions for Science Education. New York: Springer, 2015, p. 193-206.

HODSON, D. Teaching and learning science: Towards a personalized approach. Buckingham: Open University Press, 1998.

HODSON, D. Time for action: science education for an alternative future. International Journal of Science Education, v. 25, n. 6, p. 645-670, 2003.

HODSON, D. Looking to the future: building a curriculum for social activism. Rotterdam: Sense Publishers, 2011.

HODSON, D. Becoming part of the solution: Learning about activism, learning through activism, learning from activism. In: BENCZE, L.; ALSOP, S. (ed.). Activist science and technology education. Dordrecht, The Netherlands: Springer, 2014, p. 67-98.

IRETON, C.; POSENTTI, J. Introduction in Journalism, 'Fake News e Disinformation: Handbook for Journalism Education and Training. Paris: UNESCO, 2018.

JACKSON, D. et al. EU referendum analysis 2016: Media, voters and the campaign: Early reflections from leading UK academics. Bournemouth, UK: The Centre for the Study of Journalism, Culture and Community, 2016.

KAHNE, J. et al. The Civic and Political Significance of Online Participatory Cultures among Youth Transitioning to Adulthood. Journal of Information Technology and Politics, v. 10, n. 1, p. 1-20, 2013.

KELLNER, D. Cultura da mídia e triunfo do espetáculo. In: MORAES, D. (org.). Sociedade mediatizada. Rio de Janeiro: Mauad, 2006, p. 119-148.

KELLNER, D.; KIM, G. YouTube, critical pedagogy, and media activism. The Review of Education, Pedagogy, and Cultural Studies, v. 32, n. 1, p. 3-36, 2010.

KIRBY, P.; LAWS, S. Advocacy for children in family group conferences: Reflections on personal and public decision-making. In: PERCY-SMITH, B.; THOMAS, N. (ed). A handbook of children and young people's participation: perspectives from theory and practice. London: Routledge, 2010, p. $113-120$.

KOLST $\varnothing$, S. Scientific literacy for citizenship: Tools for dealing with the science dimension of 
controversial socioscientific issues. Science Education, v. 85, n. 3, p. 291-310, 2001.

KRSTOVIC, M. Preparing students for self-directed research-informed actions on socioscientific issues. In: BENCZE, L.; ALSOP, S. (ed.). Activist science and technology education. Dordrecht, The Netherlands: Springer, 2014, p. 399-417.

LANIER, J. Ten Arguments for Deleting Your Social Media Accounts Right Now. London: Henry Holt and Co., 2018.

LEVINSON, R. et al. (ed.). Creative encounters: New conversations in science, education and the arts. London: The Wellcome Trust, 2008.

LINHARES, E. F.; REIS, P. Interactive exhibition on climate geoengineering: empowering future teachers for sociopolitical action. Sisyphus - Journal of Education, v. 5, n. 3, p. 85-106, 2017.

LOPES, P. Mentiras, Pegadas e algoritmos: Da necessidade de uma educação para os media. In: LOPES, P.; REIS, B. (ed.), Comunicação digital: Media, Práticas e Consumos. Lisboa: Núcleo de Investigação em Práticas \& Competências Mediáticas, Departamento de Ciências da Comunicação da Universidade Autónoma de Lisboa, 2019, p. 137-156.

MARQUES, A. R.; REIS, P. Producción y difusión de vídeos digitales sobre contaminación ambiental. Estudio de caso: Activismo colectivo basado en la investigación. Revista Eureka sobre Enseñanza y Divulgación de las Ciencias, v. 14, n. 1, p. 215-226, 2017a.

MARQUES, A. R.; REIS, P. Research-Based Collective Activism Through the Production and Dissemination of Vodcasts About Environmental Pollution in the 8th Grade. Sisyphus - Journal of Education, v. 5, n. 2, p. 116-137, 2017b.

MARTINEZ, A. M.; ALSOP, S. Climate change and citizen science: early reflections on long-term ecological monitoring projects in Southern Ontario. In: BENCZE, L.; ALSOP, S. (ed.). Activist science and technology education. Dordrecht, The Netherlands: Springer, 2014, p. 477-489.

MCDONNELL, K. Honey, We Lost The Kids: Re-thinking childhood in the multi-media age. Melbourne: Pluto Press, 2005.

MENEZES, I. et al. (2012). Agência e participação cívica e política de jovens. In: MENEZES, I. et al. (ed.). Agência e participação cívica e política: Jovens e imigrantes na construção da democracia. Porto: Livpsic, 2012, p. 9-26.

MUELLER, M. P.; TIPPINS, D. J. Citizen science, ecojustice, and science education: Rethinking an education from nowhere. In: FRASER, B. J. et al. (ed.), Second international handbook of science education. Dordrecht, The Netherlands: Springer, 2012, p. 865-882.

MUELLER, M. P.; TIPPINS, D. J. (ed.). EcoJustice, Citizen Science and Youth Activism. Situated Tensions for Science Education. New York: Springer, 2015.

PANCER, S. M. The Psychology of Citizenship and Civic Engagement. Oxford: Oxford University Press, 2015.

PELLS, K. 'No one ever listens to us': challenging obstacles to the participation of children and young people in Rwanda. In: PERCY-SMITH, B.; THOMAS, N. (ed). A handbook of children and young people's participation: perspectives from theory and practice. London: Routledge, 2010, 
p. 196-203.

PERCY-SMITH, B.; THOMAS, N. (ed.). A handbook of children and young people's participation: perspectives from theory and practice. London: Routledge, 2010.

PETERSON, T. H. Student Development and Social Justice: Critical Learning, Radical Healing, and Community Engagement. London: Palgrave Macmillan, 2018.

REIS, G. et al. Provoking EcoJustice. Taking Citizen Science and Youth Activism Beyond the School Curriculum. In: MUELLER, M. P.; TIPPINS, D. J. (ed). EcoJustice, Citizen Science and Youth Activism. Situated Tensions for Science Education. New York: Springer, 2015, p. 39-62.

REIS, P. Da discussão à ação sócio-política sobre controvérsias sócio-científicas: uma questão de cidadania. Ensino de Ciências e Tecnologia em Revista, v. 3, n. 1, p. 1-10, 2013.

REIS, P. Promoting students' collective socio-scientific activism: Teacher's perspectives. In: BENCZE, L.; ALSOP, S. (ed.). Activist science and technology education. Dordrecht, The Netherlands: Springer, 2014, p. 547-574.

REIS, P. Environmental Citizenship \& Youth Activism. In: HADJICHAMBIS, A. CH. et al. (ed.). Conceptualizing Environmental Citizenship for 21st Century Education. Series "Environmental discourses in Science Education". Cham: Springer, 2020, p. 139-148.

REIS, P.; MARQUES, A. R. (coord.). As exposições como estratégia de ação sociopolítica: cenários do projeto IRRESISTIBLE. Lisboa: Instituto de Educação da Universidade de Lisboa, 2016.

REIS, P.; TINOCA, L. A avaliação do impacto do projeto "We Act" nas percepções dos alunos acerca das suas competências de ação sociopolítica. Revista Brasileira de Ensino de Ciência e Tecnologia, v. 11, n. 2, p. 214-231, 2018.

REIS, P. et al. The Impact of Student-Curated Exhibitions about Socio-Scientific Issues on Students' Perceptions regarding their Competences and the Science Classes. Sustainability, $\mathrm{n}$. 12, p. 2796, 2020.

RODRÍGUEZ, E. D. Together We Look for Answers. In: MUELLER, M. P.; TIPPINS, D. J. (ed). EcoJustice, Citizen Science and Youth Activism. Situated Tensions for Science Education. New York: Springer, 2015, p. 11-18.

ROGOFF, B. Apprenticeship in Thinking: Cognitive Development in Sociocultural Activity. New York: Oxford University Press, 1990.

ROTH, W.-M.; BARTON, A. Rethinking scientific literacy. New York: Routledge Falmer, 2004.

ROTH, W.-M.; DÉSAUTELS, J. (ed.). Science education as/for sociopolitical action. New York: Peter Lang, 2002.

ROTH, W.-M.; LEE, S. Scientific literacy as collective praxis. Public Understanding of Science, n. 11, p. 33-56, 2002.

SCHALK, S. When Students take Action: How and Why to Engage in College Student Activism. 2008. Tese. College of Arts and Science, Miami University, Miami, 2008.

SCHEID, N.; REIS, P. As tecnologias da informação e da comunicação e a promoção da discussão 
e ação sociopolítica em aulas de ciências naturais em contexto português. Ciência \& Educação, vol. 22, n. 1, p. 129-144, 2016.

SCHULZ, W. et al. Becoming citizens in a changing world: IEA international civic and citizenship education study 2016 international report. Amsterdam: IEA and Springer, 2018.

SCHUSLER, T. M.; KRASNY, M. E. Science and Democracy in Youth Environmental Action Learning "Good" Thinking. In: MUELLER, M. P.; TIPPINS, D. J. (ed). EcoJustice, Citizen Science and Youth Activism. Situated Tensions for Science Education. New York: Springer, 2015, p. 363-384.

SCHUTZ, A. Empowerment: A Primer. New York: Routledge, 2019.

SEGERBERG, A.; BENNETT, W. L. Social Media and the Organization of Collective Action: Using Twitter to Explore the Ecologies of Two Climate Change Protests. The Communication Review, v. 14, n. 3, p. 197-215, 2011.

SIMONNEAUX, J.; SIMONNEAUX, L. Educational configurations for teaching environmental socioscientific issues within the perspective of sustainability. Research in Science Education, $\mathrm{n}$. 42, p. 75-94, 2012.

SLEETER, C. E.; CORNBLETH, C. Teaching with vision: Culturally responsive teaching in standardsbased classrooms. New York: Teachers College Press, 2011.

STEGMANN, K. et al. Facilitating argumentative knowledge construction with computersupported collaboration scripts. Computer-Supported Collaborative Learning, n. 2, p. 421-447, 2007.

STEVENSON, B. American injustice: Mercy, humanity and making a difference. Criminal justice symposium. Claremont: Pomona College, 2016.

TIPPINS, D. et al. (ed.). Cultural studies and environmentalism: The confluence of ecojustice, place-based (science) education, and indigenous knowledge. Dordrecht: Springer, 2010.

TWUM-DANSO, A. The Construction of Childhood and the Socialisation of Children in Ghana: Implications for the implementation of article 12 of the CRC. In: PERCY-SMITH, B.; THOMAS, N. (ed). A handbook of children and young people's participation: perspectives from theory and practice. London: Routledge, 2010, p. 133-140.

VAIDHYANATHAN, S. Antisocial Media: How Facebook Disconnects Us and Undermines Democracy. New York: Oxford University Press, 2018.

VALSINER, J. Culture and Human Development. Thousand Oaks: Sage, 2000.

VYGOTSKY, L. S. Mind and Society. Cambridge: Harvard University Press, 1978.

WARDLE, C. Understanding Information Disorder. London: First Draft, 2019.

WARDLE, C.; DERAKHSHAN, H. Information disorder: Toward an inter-disciplinary framework for research and policymaking. Strasbourg: Council of Europe, 2017.

WATANABE, G.; REIS, P. Controvérsias sócio-científicas e relações de poder: desafios de sua inserção segundo futuros professores de ciências. Linhas Críticas, n. 24, p. 472-496, 2019.

WHITE, S.; CHOUDHURY, S. Children's participation in Bangladesh: issues of agency and 
structures of violence. In: PERCY-SMITH, B.; THOMAS, N. (ed). A handbook of children and young people's participation: perspectives from theory and practice. London: Routledge, 2010, p. 3950.

YAMASHITA, H.; DAVIES, L. Students as Professionals. In: PERCY-SMITH, B.; THOMAS, N. (ed). A handbook of children and young people's participation: perspectives from theory and practice. London: Routledge, 2010, p. 230-239.

ZORAS, B.; BENCZE, L. Utilizing social media to increase student-led activism on STSE issues. In: BENCZE, L.; ALSOP, S. (ed.). Activist science and technology education. Dordrecht, The Netherlands: Springer, 2014, p. 435-449. 